\title{
ANALYZING DRIVING ENVIRONMENT FACTORS IN PEDESTRIAN CRASHES INJURY LEVELS IN JAKARTA AND THE SURROUNDING CITIES
}

\author{
Martha Leni Siregar ${ }^{1 *}$, R. Jachrizal Sumabrata ${ }^{1}$, Andyka Kusuma ${ }^{1}$, Omas Bulan Samosir ${ }^{2}$, Silvanus Nohan \\ Rudrokasworo ${ }^{1}$
}

${ }^{1}$ Faculty of Engineering, Universitas Indonesia, Indonesia

${ }^{2}$ Faculty of Economics and Business, Universitas Indonesia, Indonesia

\begin{abstract}
Pedestrian-vehicle crashes are the results of a combination of influencing factors including the driving enviroment. This paper looks into the driving environment factors in pedestrian crashes injury levels on road links in Jakarta and the surounding cities which contribute to the city traffic generation. The vehicle-pedestrian accident data used were obtained from the 2016 Indonesian national police accident database covering 4,646 pedestrian accidents on road links from Jakarta, Depok, Tangerang Selatan, Tangerang and Bekasi, Indonesia. Various factors were analyzed including crash level severity, month of occurrence, weather condition, lighting condition, road function, road class, road type, road surface condition and road status. As injury levels were categorized into slight injury, severe injury and fatal injury and it was assumed that the dependent variables which were crash injury levels could not be perfectly predicted from the independent variables, Multinomial logistic regression (MNL) was used in the analysis to predict the probability of different categories of dependent variables. It was found that the relative risks of pedestrian accident risks factors changed with different categories both in terms of fatal and severe injuries. One of the findings shows that the risk of having severe injuries would decrease by $40.2 \%$ on national roads, by $70.5 \%$ on provincial roads and by $53.5 \%$ on urban roads. The results can be expected to be referred to in the improvement of pedestrian safety level and in the development of related measures.
\end{abstract}

Key words: lighting, driving environment risk factors; pedestrian-vehicle crash; pedestrian crash severity; road function, MNL, injury, variability, drive

\section{INTRODUCTION}

WHO (World Health Organization) states that more than half of all road traffic deaths are among vulnerable road users: pedestrians, cyclists, and motorcyclists [1]. Vulnerable road users are also defined as those sustaining the greater risks in road traffic. Pedestrians are generally defined as those most at risk for serious injury or death when involved in a road accident particularly in terms of fatalities and serious injuries [2]. Traffic crashes are the results of a combination of different factors that work individually or interactively within a road system. With different contributing factors, the main causes, types, and levels of severity of crashes are never identical in different cases. Identifying the road driving environment risk factors will help reduce the crashes frequency and lower the level of severity. Previous researchers developed various models that accommodate road geometric and road characteristics, traffic and environmental factors in addition to speed related factors. Moudon et al. [3] found that road characteristics (multiple lanes and surface conditions etc.) contribute to crash occurrence and Retting et al. [4] indicated that street types (residential, freeway, arterial), intersections, and street design features including lighting are associated with vehicle-pedestrian collision and a much earlier research [5] agreed on traffic volume as a significant factor in vehicle-pedestrian collisions. The speed of vehicle was found to be a significant factor that affects the level of injury severity [6] and speed limit is also a determining factor in the probability of pedestrian accident fatality [7], [8], [9]. A study in Kenya indicated that improved road condition leads to higher speed which also causes more pedestrians hit by vehicles [10]. Pour-Rouholamin [11] investigated pedestrian injury risk factors in Illinois. Using ordered-response models, the study concluded that severe injuries were related to a number of different variables such as divided highways, highways with multi lanes, lighting condition, and heavies. Drivers have to pay attention to the environment while driving which causes a multi-tasking driving as in driving in a city driving environment. Complex driving situations, with traffic conflicts, cause drivers to be involved in collisions [12]. However, it was shown that more than $70 \%$ of the drivers do activities other than driving [13]. A number of researches have also been conducted to examine how complex driving environment and work load affect the task demands [14]. Road network and the driving environment, therefore, have considerable effects on crash risks because they determine how road users perceive their environment and how drivers react towards the instructions and guidance presented by the signs, markings and traffic control systems. Based on WHO [15] the number of pedestrian accident deaths in Indonesia in 2016 constitute $15.5 \%$ of the total road users accidents deaths. Jakarta, as the capital city 


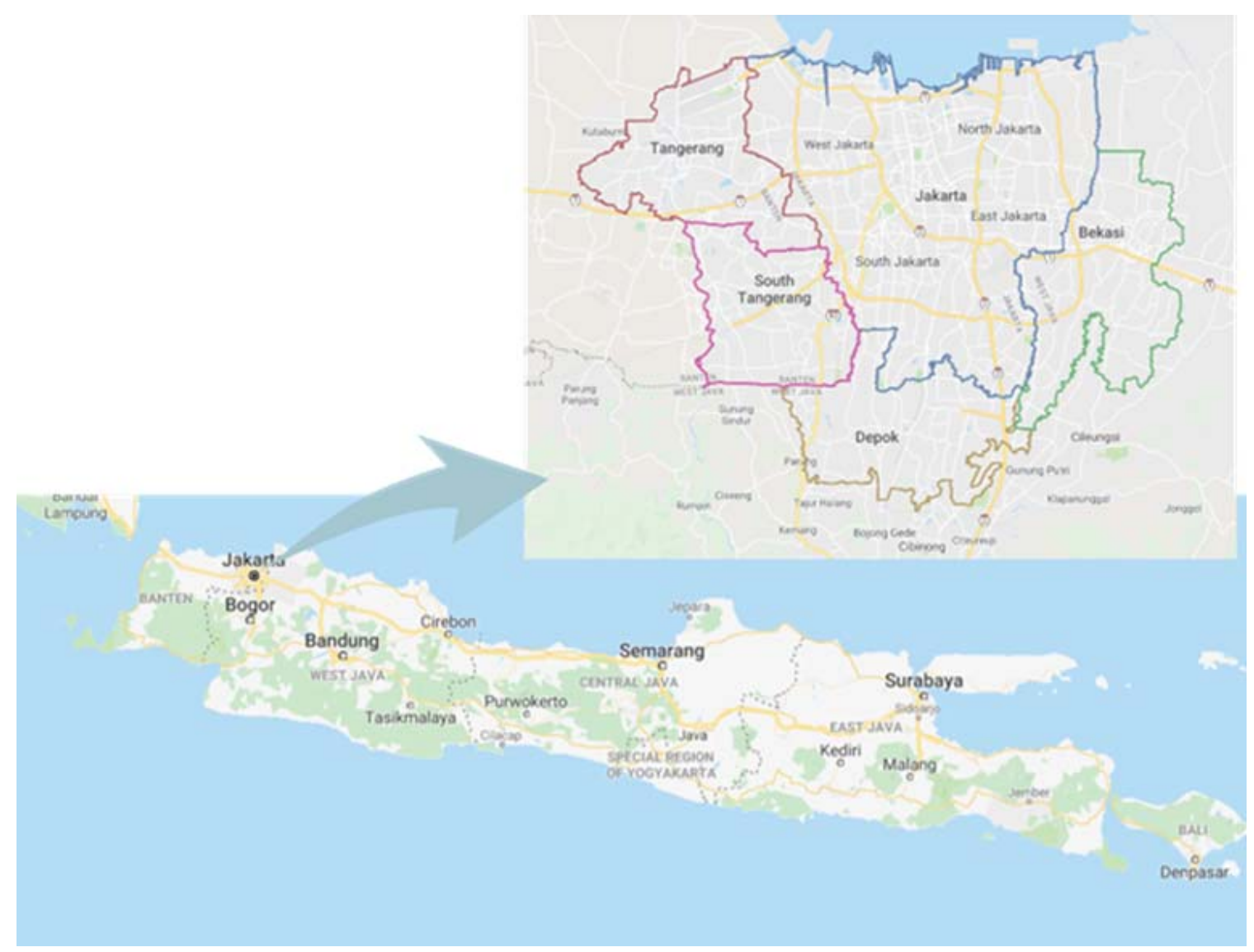

Figure 1: Study area covering Jakarta, Depok, Tangerang, South Tangerang and Bekasi, Java Island, Indonesia

of Indonesia suffers from high traffic accident frequency and high level of service and congestions which also lead to traffic safety problems. With the total number of 4,646 records of pedestrian accidents in 2016 from Jakarta and the immediate neighboring municipalities: Depok, Tangerang, South Tangerang and Bekasi (Fig. 1) (IRSMS) [16], an in-depth analysis of how changes in different factors affect the levels of severity of pedestrian accidents is of paramount importance.

\section{RESEARCH METHOD}

\section{Data categorization}

Applying the principle of System theory in accident occurrences which proposes that crashes are the resultant of maladjustments of a set of interactions within the road environment [4], [5], this study analyses the potential factors in road accident severity which include the driving environment factors in Jakarta and the surrounding cities. Based on previous studies on various significant factors in pedestrian crashes occurrences [4], [11], [17], the present study investigates how month, weather, lighting condition, road function, road class, road type, road status and road surface conditions affect pedestrian accident severity risks.

Different road classifications serve different allowable axle loading which therefore accommodates different types of vehicles with different axle loads. Road status refers to road authorities in charge of developing road and road network, construction and maintenance of the road. With different authorities, roads of the same types may have different road environment characteristics. The data in the present study do not differentiate individual cities and are used as one set of panel data to enable a thorough analysis based on the varied driving conditions of pedestrian crashes and to allow inclusion of all types of category. Pedestrian crash injury levels are categorized into slight injury (with a non-incapacitating injury that needs medical attention), severe injury (when the victim is hospitalized for more than 30 days or with an incapacitating injury or is in hospital up to 30 days), and fatal injury (when the victim dies within 30 days after the accident).

The coverage of the area is expected to give a representative description of driving environment and the potential factors in road crashes. Data used in this study were pedestrian crash data 2016 from the Indonesian traffic police which are classified and categorized into: Levels of crash severity (slight injury, serious injury and fatal crashes), months of occurrences (January-June and July-December), lighting condition (bright, moderate and dark), weather condition (clear and unfavorable), road function (arterial, collector, local and toll road), road classes (class 1, class 2 and class 3), road types (undivided and divided), road geometric types, road surface condition (good and poor), road gradient, road status 
(national, provincial, urban and rural). The road function, class, type, surface condition and status refer to the geometric design guidelines for inter-urban roads applied in Indonesia [18].

\section{Multinomial logistic regression}

Collision models have been developed from various perspectives and approaches to describe the relationships between variables Crashes are often separately modelled into frequency and level of severity. Among the commonly adopted analysis are multinomial logit that looked into pedestrian-vehicle severity crash [19], multivariate tobit [17], [20] in analyzing highway accident-injury-severity rates, hierarchical ordered models [21] that modelled crash outcome probabilities, mixed logit for Highway accident severities [22], mixed-logit mode applied in pedestrian-injury severity analysis in motor vehicle crashes [23], random-parameters Tobit model to study factors affecting accident rates [20]. Bayesian models [24], and ordered response models [25], [26]. It was also found that compared to the conventional ordered (proportional odds-PO) model and generalized ordered logit model (GOLM), the partial proportional odds (PPO) model shows better analysis performance [11]. Random parameter multinomial logit models was adopted by Aziz et al. (2013) [27] to accommodate the variation across observations as assumptions can be made for types of probabilistic distribution.

In this study, the data were analyzed descriptively and inferentially. Descriptively, the percentage distribution of pedestrian crash severity is given, including the influencing factors in the model. Inferentially, a multinomial logistic regression (MNL) was adopted to investigate the factors affecting the pedestrian crash severity as it is suitable for cases where the response variable is composed of more than two categories and it allows simultaneous comparison of more than one contrast. MNL was generalized from binary logistic regression which only considers two values of categorical response variables [28]. In MNL, the log odds of more than two contrasts can be estimated simultaneously where the odds ratios explains the impact of predictor variables. MNL regression takes no assumption of normality, linearity or homoscedasticity of sample variances, but there is independence among the dependent variable choices. The explanatory variables were determined from the accident data base that were considered potential in pedestrian crash occurrences.

The multinomial logistic regression expresses the relationship between the probability of an observation falling in the jth category with i explanatory variables $X_{i}$ as follows:

The dependent variable of the model is pedestrian crash severity $(Y)$, which is categorized as Slight injury $(Y=0)$, severe injury $(Y=1)$ and fatal accident $(Y=2)$. The independent variables are months of accident occurrence $\left(X_{1}\right)$, weather condition $\left(X_{2}\right)$, lighting condition $\left(X_{3}\right)$, road function $\left(X_{4}\right)$, road class $\left(X_{5}\right)$, road type $\left(X_{6}\right)$, road status $\left(X_{7}\right)$ and road surface condition $\left(X_{8}\right)$.

$p_{i}$ is the multinomial probability of $Y=j$ ( $p_{2}=$ fatal accident probability, $p_{1}=$ severe injury probability, and $p_{0}=$ slight injury probability), $\beta_{j 0}$ is the intercept for the $j^{\text {th }}$ $(j=1,2), \beta_{j k}$ is the parameter for independent variable $k^{\text {th }}, X_{k}(k=1,2, \ldots, 8)$, for the logistic regression function jth, $g_{j}(x)$ and $\varepsilon_{j}$ are errors in the $j^{\text {th }}$ logistic regression function.

When there is $n$ independent observations with $p$ explanatory variables, and the response variable has $J$ categories, a base level has to be determined to which logits are constructed relative. Although the interpretation of the parameters will change, the choice of variable for the reference category does not necessarily impact the model fitting as it will result in the same likelihood and fitted values.

\section{RESULTS AND DISCUSSION}

An Intercept Only model without any explanatory variables was produced to compare with a Final model with all explanatory variables in the model fitting to check whether the model improves the outcome predictability (crash severity). The result indicates that the dependent variable is better predicted in the full model than in the intercept-only model $(p$ value $=0.000)$. The pseudo R-Square values (Nagelkerke $=6.7 \%$ ) indicates that the variation between crash severity modalities is explained in a relatively small proportion. The likelihood ratio tests as shown in Table 1 reveals that weather (clear weather), road class, road type, and road gradient, are not statistically significant because their $\mathrm{p}$-values are higher than 5\% (the 'Sig.' column). On the contrary, month (Jan-Jun), lighting, road function, road geometric, road conditions, and road status are statistically significant because their p-values are less than $5 \%$, which is also reflected by other findings [4], [11], [13].

The reference category used in this analysis is slight injury. For a unit change in the predictor variable, the logit of outcome relative to the reference group is expected to change by its respective parameter estimate given the variables in the model are held constant. To determine factors influencing traffic crash severity levels, the p-value ('Sig.' column) of the estimate coefficients for each factor in the two different models are analyzed, and interpretation is made using the odds ratios (column 'Ex$\mathrm{p}(\mathrm{B})$ ') of the predictors. (see Table 2). For the first model (fatal injury relative to slight injury), the Wald test statistic for predictors: dark lighting, bright lighting, undivided road type, intersection road, poor road surface, provincial road, urban road, are associated, with a p-value less

$g_{j}(x)=\ln \left(\frac{p_{j}}{p_{0}}\right)=\beta_{j 0}+\beta_{j 1} X_{1}+\beta_{j 2} X_{2}+\beta_{j 3} X_{3}+\beta_{j 4} X_{4}+\beta_{j 5} X_{5}+\beta_{j 6} X_{6}+\beta_{j 7} X_{7}+\beta_{j 8} X_{8}+\varepsilon_{j}$ 
than $5 \%$, so the null hypothesis was rejected and it was concluded that there is a statistical influence of those factors on the model. This is in line with the findings of other researches [3], [4]. For example, for the road type factors, the 'Wald' test statistics for the predictor 'undivided road type' is 4.338 with an associated p-value of 0.037 . For alpha of $5 \%$, the null hypothesis was rejected and it was concluded that the regression coefficient for undivided road is statistically different from zero given the other factors in the model. For the second model (severe injury relative to slight injury), the Wald test statistic for predictors: January to June, dark lighting, bright lighting, arterial road, (Road_class $=1$ ), national road (Road status=1), provincial road (Road status=2), urban road (Road status $=3$ ) are associated with a p-value less than $5 \%$, so again, the null hypothesis was rejected and it was indicated that the factors statistically influence the model.

The relative risk ratio comparing dark lighting to moderate lighting (reference modality) for fatal injury relative to slight injury model given that the other variables in the model are held constant (in their referent modality), the relative risk would be expected to increase by a factor of 2.347 (134\%) and for severe injury 2.362 (236.2\%). For bright lighting compared to moderate lighting, the risk of having a fatal injury relative to slight injury would be expected to decrease by a factor $0.633(36.7 \%)$ and risk of having severe injury in dark lighting condition decrease by 0.705 . Bright condition clearly provides higher visibility of pedestrian in particular when crossing the streets. Minimum lighting impacts the peripheral obstacle detection [29]. and also causes drivers' shorter sight distances leading to insufficient stopping distance as signified by the highly increased risk of dark lighting relative to moderate lighting. Lighting condition was also found to increase pedestrian injury severity together with other factors. [11].
The study by Azis et al. [27] concluded different effects with both positive and negative association of dark road condition in different boroughs in NY city. Reduced visibility was found to contribute to night time pedestrian fatalities where even with the presence of glare only $61 \%$ of pedestrians were identified [30]. Other studies indicate similar findings that night-time is one of the potential risk factors for pedestrian [31][32]. The relative risks of having fatal or severe injuries to slight injury at both types of intersections decrease compared to the pedestrian crashes on straight roads with factors $0.836,0.416$ for severe injury and 0.531 and 0.739 for fatal injury. Curves, however reveal increased risks of both fatal and severe injuries with much bigger factors 1.371 and 1.151. This finding agrees with a study by Wang [29] that concluded road horizontal curvature has mixed effects on road safety. The relative risk ratio of pedestrian crashes occurring at intersections decreases compared to straight road by $4.69 \%$ indicating that fatal injuries are unlikely to occur at intersections. Drivers reduce their speed when approaching intersections in particular at intersections without traffic control and halt during red, as also found by another study [22]. This may be related to driver's bigger efforts in driving maneuvers along curves to counter the centrifugal force in particular at curves with inadequate superelevations. This is also in line with Siregar [33] who suggested that road safety can be improved by changing the patterns of traffic interactions through road design features changes.

Driver's limited sight distances along curves can prevent drivers from making the right maneuvers to avoid hitting pedestrians. In addition, pedestrians may not perceive that curves are not a very safe road section for pedestrians as indicated by a previous study by Rankavat and Tiwari (2016) which revealed that pedestrians do not perceive actual high crash locations high risk [30].

Road type, as classified into divided or undivided road

Table 1: Likelihood Ratio Tests

\begin{tabular}{|l|c|c|c|c|}
\hline \multirow{2}{*}{ Effect } & Model Fitting Criteria & \multicolumn{2}{c|}{ Likelihood Ratio Tests } \\
\cline { 2 - 5 } & -2 Log Likelihood of Reduced Model & Chi-Square & df & Sig. \\
\hline Intercept & $2107.338 a$ & .000 & 0 &. \\
\hline Jan-Jun & 2113.951 & 6.613 & 2 & .037 \\
\hline Lighting & 2201.834 & 94.496 & 4 & .000 \\
\hline Clear weather & 2107.579 & .241 & 2 & .886 \\
\hline Road_Function & 2148.123 & 40.786 & 6 & .000 \\
\hline Road_Class & 2114.204 & 6.866 & 4 & .143 \\
\hline Road_Type & 2111.712 & 4.374 & 2 & .112 \\
\hline Road_Geometric_Type & 2136.453 & 29.115 & 6 & .000 \\
\hline Road_Surface_Condition & 2121.117 & 13.779 & 2 & .001 \\
\hline Road_Gradient & 2107.542 & .205 & 2 & .903 \\
\hline Road_Status & 2176.512 & 69.174 & 6 & .000 \\
\hline
\end{tabular}


has been found to be responsible for pedestrian crashes [31] In the present work, the absence of medians on undivided roads leads to $17.3 \%$ increase in the relative risk of fatal injuries compared to divided roads and $5.7 \%$ increase of relative risk of severe injury. With no refuge area to wait before continuing crossing, pedestrians are exposed to higher risks of being hit. This implies that fatal crash injuries tend to occur on undivided roads compared to divided roads which may be due to the minimum physical protection drivers can be provided with when crossing undivided roads.

Poor road surface condition causes an increase of $75.7 \%$ in the relative risk fatal crash but causes a decrease of $28.1 \%$ of severe injury relative risk compared to roads with good surface condition. Fatal injuries have the tendency to occur on roads with poor surface conditions. The categorization of road surface condition in this study is qualitative as the crash data do not use quantitative values such as IRI (international roughness index). Poor road condition causes lower traffic speed with relatively high individual vehicle speed deviations which may confuse pedestrians in deciding on accepted gap for crossing the street. That the risks for fatal crash increases and for severe crash decrease suggests that severe pedestrians crash injury occurring on roads with poor surface condition tend to shift to fatal injury. With minimum lighting, poor road condition can become an unexpected obstacle over which pedestrians may trip and fall, and be exposed to having a crash with higher injury level [32].

The relative risk comparing national roads (0.598), provincial roads $(0.295)$ and urban roads $(0.465)$ to rural roads (reference category) shows us that the risk of having severe injuries would decrease by $40.2 \%$ on nation- al roads, by $70.5 \%$ on provincial roads and by $53.5 \%$ on urban roads. For fatal crash, the relative risks of the different road status all decrease by $6,4 \%, 48.1 \%$ and $35.4 \%$. A possibility is the presence of pedestrian facilities on national, provincial and urban road that are provided contributes to the higher pedestrian safety. The road status classification is based on the road authority of related level of government in charge of road management including road maintenance. The decrease of relative risks indicate that rural road which is used as the reference category has the highest pedestrian crash risks both in terms of severity and fatality. This finding is in line with the work of Lee and Abdelaty [34] who concluded that compared to urban roads, rural roads were more associated with higher pedestrian crash severity. Borowsky also discovered that road status contributes significantly to the level of pedestrian crash severity [35]. However, the results are contradictory as the research concluded that national roads and urban roads show higher pedestrian crash proneness and that pedestrians are more easily identified in residential areas than in urban areas. The discrepancy in the findings may be due to the different definitions of road classifications and the provision of pedestrian facilities.

Arterial roads, compared to toll road as the reference category, indicates that the risk of severe injury increases by $127.6 \%$. This may be due to the possibility of higher concentration of pedestrian-vehicle crashes on arterial roads as also indicated by Gitelman [36] who revealed that arterial multi-lane streets belonging to city centers have the majority of high concentration of pedestrianvehicle crashes.

Table 2: Parameter Estimates

\begin{tabular}{|c|c|c|c|c|c|c|c|c|c|}
\hline \multirow{2}{*}{\multicolumn{2}{|c|}{$\begin{array}{c}\text { Crash_Classification (Reference } \\
\text { category: Slight Injury) }\end{array}$}} & \multirow{2}{*}{ B } & \multirow{2}{*}{$\begin{array}{l}\text { Std. } \\
\text { Error }\end{array}$} & \multirow{2}{*}{ Wald } & \multirow{2}{*}{ df } & \multirow{2}{*}{ Sig. } & \multirow{2}{*}{$\begin{array}{l}\text { Ex- } \\
p(B)\end{array}$} & \multicolumn{2}{|c|}{$\begin{array}{l}\text { 95\% Confidence } \\
\text { Interval for Exp(B) }\end{array}$} \\
\hline & & & & & & & & Lower & Upper \\
\hline \multirow{20}{*}{ Severe injury } & Intercept & .686 & .486 & 1.989 & 1 & .158 & & & \\
\hline & Jan-Jun & .191 & .076 & 6.351 & 1 & .012 & 1.211 & 1.043 & 1.405 \\
\hline & Jul-Dec & 0 & & & 0 & & & & \\
\hline & Dark lighting & 1.212 & .220 & 30.414 & 1 & .000 & 3.362 & 2.185 & 5.172 \\
\hline & Bright lighting & -.350 & .096 & 13.305 & 1 & .000 & .705 & .584 & .851 \\
\hline & Moderate lighting & 0 & & & 0 & & & & \\
\hline & Clear weather & -.098 & 209 & .221 & 1 & .639 & .906 & .601 & 1.366 \\
\hline & Unfavorable weather & 0 & & & 0 & & & & \\
\hline & Arterial road & .823 & 219 & 14.082 & 1 & .000 & 2.276 & 1.481 & 3.498 \\
\hline & Collector & .327 & .365 & .799 & 1 & .371 & 1.386 & .677 & 2.838 \\
\hline & Local road & -.509 & .391 & 1.693 & 1 & .193 & .601 & 279 & 1.294 \\
\hline & Toll road & 0 & & & 0 & & & & \\
\hline & Road class 1 & -.794 & .335 & 5.614 & 1 & .018 & .452 & .234 & .872 \\
\hline & Road class 2 & -.850 & .455 & 3.487 & 1 & .062 & 428 & .175 & 1.043 \\
\hline & Road class 3 & 0 & & & 0 & & & & \\
\hline & Undivided road & .055 & .083 & .449 & 1 & .503 & 1.057 & .899 & 1.243 \\
\hline & Divided road & 0 & & & 0 & & & & \\
\hline & Curve & .141 & .214 & .434 & 1 & .510 & 1.151 & .757 & 1.752 \\
\hline & Intersection (2-4 leg) & -.179 & .126 & 2.021 & 1 & .155 & .836 & .653 & 1.070 \\
\hline & Multi-leg intersection & -.876 & 1.132 & .599 & 1 & .439 & .416 & .045 & 3.827 \\
\hline
\end{tabular}




\begin{tabular}{|c|c|c|c|c|c|c|c|c|c|}
\hline \multirow{2}{*}{\multicolumn{2}{|c|}{$\begin{array}{c}\text { Crash_Classification (Reference } \\
\text { category: Slight Injury) }\end{array}$}} & \multirow{3}{*}{$\begin{array}{l}\text { B } \\
0\end{array}$} & \multirow{3}{*}{$\begin{array}{l}\text { Std. } \\
\text { Error }\end{array}$} & \multirow{2}{*}{ Wald } & \multirow{2}{*}{ df } & \multirow{2}{*}{ Sig. } & \multirow{3}{*}{$\begin{array}{l}E x- \\
p(B)\end{array}$} & \multicolumn{2}{|c|}{$\begin{array}{l}95 \% \text { Confidence } \\
\text { Interval for } \operatorname{Exp}(B)\end{array}$} \\
\hline & & & & & & & & Lower & Upper \\
\hline \multirow{9}{*}{ Severe injury } & Straigth section & & & & 0 & & & & \\
\hline & Poor & -.329 & 287 & 1.323 & 1 & .250 & .719 & .410 & 1.261 \\
\hline & Good & 0 & & & 0 & & & & \\
\hline & Gradient & -.001 & .215 & .000 & 1 & .995 & .999 & .656 & 1.521 \\
\hline & Flat & 0 & & & 0 & & & & \\
\hline & National road & -.515 & .235 & 4.779 & 1 & .029 & .598 & .377 & .948 \\
\hline & Provincial road & -1.221 & .218 & 31.504 & 1 & .000 & .295 & .192 & .452 \\
\hline & Urban road & -.766 & .203 & 14.203 & 1 & .000 & .465 & .312 & .692 \\
\hline & Rural road & 0 & & & 0 & & & & \\
\hline \multirow{29}{*}{ Fatal Injury } & Intercept & .574 & .403 & 2.022 & 1 & .155 & & & \\
\hline & Jan-Jun & .039 & .070 & .304 & 1 & .582 & 1.039 & .906 & 1.193 \\
\hline & Jul-Dec & 0 & & & 0 & & & & \\
\hline & Dark lighting & .853 & .218 & 15.365 & 1 & .000 & 2.347 & 1.532 & 3.595 \\
\hline & Bright lighting & -.457 & .088 & 27.013 & 1 & .000 & .633 & .533 & .752 \\
\hline & Moderate lighting & 0 & & & 0 & & & & \\
\hline & Clear weather & -.014 & .193 & .005 & 1 & .943 & .986 & .676 & 1.439 \\
\hline & Unfavorable weather & 0 & & & 0 & & & & \\
\hline & Arterial road & .086 & .170 & .255 & 1 & .614 & 1.090 & .780 & 1.522 \\
\hline & Collector & -.147 & .308 & .229 & 1 & .632 & .863 & .472 & 1.577 \\
\hline & Local road & -.517 & .294 & 3.078 & 1 & .079 & .597 & .335 & 1.062 \\
\hline & Toll road & 0 & & & 0 & 0. & & & \\
\hline & Road class 1 & -.186 & .254 & .540 & 1 & .463 & .830 & .505 & 1.364 \\
\hline & Road class 2 & -.034 & .370 & .008 & 1 & .927 & .967 & .469 & 1.995 \\
\hline & Road class 3 & 0 & & & 0 & & & & \\
\hline & Undivided road & .160 & .077 & 4.338 & 1 & .037 & 1.173 & 1.009 & 1.364 \\
\hline & Divided road & 0 & & & 0 & & & & \\
\hline & Curve & .316 & .190 & 2.770 & 1 & .096 & 1.371 & .946 & 1.988 \\
\hline & Intersection (2-4 leg) & -.633 & .132 & 22.890 & 1 & .000 & .531 & .409 & .688 \\
\hline & Multi-leg intersection & -.302 & .876 & .119 & 1 & .730 & .739 & .133 & 4.117 \\
\hline & Straigth section & 0 & & & 0 & & & & \\
\hline & Poor & .563 & .223 & 6.403 & 1 & .011 & 1.757 & 1.135 & 2.718 \\
\hline & Good & 0 & & & 0 & & & & \\
\hline & Gradient & .078 & .191 & .168 & 1 & .682 & 1.082 & .743 & 1.574 \\
\hline & Flat & 0 & & & 0 & & & & \\
\hline & National road & -.066 & .230 & .082 & 1 & .775 & .936 & .597 & 1.470 \\
\hline & Provincial road & -.656 & .213 & 9.520 & 1 & .002 & .519 & .342 & .787 \\
\hline & Urban road & -.437 & .201 & 4.732 & 1 & .030 & .646 & .436 & .958 \\
\hline & Rural road & 0 & & & 0 & & & & \\
\hline
\end{tabular}

Road function is found to have high Wald test statistics for arterial road (14.082 for severe injury crashes) and it is indicated that the severity risks ratio of severe and fatal crashes to slight injury on arterial roads increase compared to those of toll roads which is used as the reference. Road function determines the maximum volume that can be accommodated, level of accessibility, pedestrian facilities and allowable traffic speed. This finding is supported by a previous study that showed that crashes on high speed roads such as freeways, national roads and provincial roads have higher tendency to be fatal or serious injury rather than minor injury crashes and also studies on fatality rates and vehicle speeds [19], [37], [38]. Kröyer [39] also found that speed is potential in injury level of pedestrian crash and that roads with speed lower than $40 \mathrm{~km} / \mathrm{h}$ rarely have fatal crashes. The relative risk ratio of pedestrian crashes occurring at inter- sections decreases compared to straight road by $4.69 \%$ indicating that fatal injuries are unlikely to occur at intersections. This might be because drivers tend to reduce their speed when approaching intersections in particular at intersections without traffic control and halt during red, which is also the finding of a previous study [27].

\section{CONCLUSIONS}

Despite the relatively small $\mathrm{R}$-squares, the independent variables are found to be significant and meets the aim of this study which is to find reliable relationship between the independent variables and dependent variables. The results of the study show that the driving environment risk factors in Jakarta and the surrounding cities that significantly increase the probability of fatal injury in a pedestrian crash include lighting condition, road type, road function and road status. Road function which is catego- 
rized into arterial, collector, local, and toll road, is found to be the most highly influencing variable that determines the different levels of the severity of crash involving pedestrians. The different road functions are also related to the accessibility of the road. Higher accessibility allows lower mobility of pedestrians; the condition which may result in lower number of pedestrians and lower pedestrian crashes. With the high relative risk of dark lighting condition, road lighting is of paramount important. Provision of appropriate pedestrian crossing facilities on undivided roads will reduce the probability of fatality by more than $17 \%$. As road function is related to the road management authority, it is therefore of paramount important that the road function categories be reviewed to comply with the pedestrian access and pedestrian facilities along the roads. Upgrading a road function to a higher level should consequently be followed with improvement and upgrading the pedestrian facilities, as well as applying necessary restrictions to certain pedestrian accesses.

Efforts to reduce severe and fatal pedestrian crashes can therefore be made through changes in factors in particular factors with high odds. Changing the lighting condition to bright and improving the road surface condition can be expected to lower the level of severity. Measures are also required to prevent pedestrian crashes along curves by ensuring adequate sight distances, installation of appropriate warnings and others. The results of this study show how changes within categories of different driving environment factors can lead to lower level of pedestrian accident injuries.

\section{ACKNOWLEDGEMENT}

This work was supported by the PDUPT research grant from the Ministry of Research, Technology and Higher Education the Republic of Indonesia (contract number 411/UN2.R3.1/HKP05.00/2018)

\section{REFERENCES}

1. United Nation Road Safety Collaboration [Internet]. Available from: https://www.who.int/roadsafety/en/ [accessed Jan 5, 2019]

2. OECD Scientific Expert Group on the Safety of Vulnerable Road Users (RS7). (1998). Safety of Vulnerable Road Users. [accessed Mar 13, 2019]

3. Moudon A.V., Lin L., Jiao J., Hurvitz P., Reeves P. (2009). The risk of pedestrian injury and fatality in collisions with motor vehicles, a social ecological study of state routes and city streets in King County, Washington. Accid Anal Prev, 2011;43(1):11-24, DOI: 10.1016/j.aap.2009.12.008

4. Retting R.A., Ferguson S.A., McCartt A.T., (2003). A Review of Evidence-Based Traffic Engineering Measures Designed to Reduce Pedestrian-Motor Vehicle Crashes. Am J Public Heal; 93(9):1456-63, DOI: 10.2105/ajph.93.9.1456
5. Roberts I., Crombie I., (1995). Child pedestrian deaths: sensitivity to traffic volume evidence from the USA. J Epidemiol Community Health.;49:186-8, DOI: 10.1136/jech.49.2.186

6. Tate F., Turner S.., (2007). Road geometry and drivers speed choice. In: IPENZ Transportation Group Conference Tauranga [Internet]. Tauranga; Available from: ipenz.org.nz/ipenztg/archives.htm [accessed: December 2, 2018]

7. Davis G.A.,(2001). Relating Severity of Pedestrian Injury to Impact Speed in Vehicle-Pedestrian Crashes Simple Threshold Model. Transp Res Rec.;1773(01):108-13, DOI: 10.3141/1773-13

8. Roudsari B., Mock C., Kaufman R., Grossman D., Henary B., Crandall J. (2004). Pedestrian crashes: higher injury severity and mortality rate for light truck vehicles compared with passenger vehicles. Inj Prev.,10(3):154-8, DOI: 10.1136/ip.2003.003814

9. Wong S., Sze N., Li Y. (2007). Contributory factors to traffic crashes at signalized intersections in Hong Kong. Accid Anal Prev.,39(6):1107-13, DOI: 10.1016/j.aap.2007.02.009

10. Gichaga F.J. (2016). The impact of road improvements on road safety and related characteristics. IATSS Res.,40(2):72-5, DOI: 10.1016/j.iatSsr.2016.05.002

11. Pour-rouholamin M, Zhou H. (2016). Investigating the risk factors associated with pedestrian injury severity in Illinois. J Safety Res., 57:9-17, DOI: 10.1016/j.jsr.2016.03.004

12. Siregar M.L., Agah H.R., Hidayatullah F. Near-miss accident analysis for traffic safety improvement at a 'channelized' junction with U-turn. Int J Saf Secur Eng. 2018;8(1). DOI: 10.2495/SAFE-V8-N1-31-38

13. Javid, A. M., \& Al-Neama, Y. M. [2018]. Identification of factors causing driver's distraction in Oman. Journal of Applied Engineering Science, 16(2), 153-160.

14. Bongiorno N., Bosurgi G., Pellegrino O., Sollazzo G. (2017). How is the Driver's Workload Influenced by the Road Environment? Procedia Eng.,187:2-13, DOI: 10.1016/j.proeng.2017.04.343

15. WHO [Internet]. [cited 2018 Mar 23]. Available from: https://www.who.int/violence_injury_prevention/ road_safety_status/2018/en/

16. IRSMS [Internet]. [cited 2018 Mar 23]. Available from: korlantas.info

17. Ulfarsson G.F., Kim S., Booth K.M. (2010), Analyzing fault in pedestrian - motor vehicle crashes in North Carolina. Accid Anal Prev., 42(6):1805-13, DOI: 10.1016/j.aap.2010.05.001

18. Perencanaan Geometrik Jalan Antar Kota No. 038/ TBM/1997. Direktorat Jenderal Bina Marga, Departemen Pekerjaan Umum Republik Indonesia; 
19. Tay R., Choi J., Kattan L., Khan A. (2011), A Multinomial Logit Model of Pedestrian-Vehicle Crash Severity. Int J Sustain Transp.,5(4):233-49, DOI: 10.1 080/15568318.2010.49754710.1080/15568318.201 0.497547

20. Anastasopoulos P.C., Mannering F.L., Shankar V., Haddock JE. (2011). A study of factors affecting highway accident rates using the random-parameters Tobit model. Accid Anal Prev., 45:628-33, DOI: 10.1016/j.aap.2011.09.015

21. Kim M., Kho S-Y., Kim D-K. (2017). Hierarchical ordered model for injury severity of pedestrian crashes in South Korea. J Safety Res., 61:22-40, DOI: 10.1016/j.jsr.2017.02.011

22. Milton J., Shankar V., Mannering F. (2008). Highway accident severities and the mixed logit model: an exploratory empirical analysis. Accid Anal Prev. , 40:260-6, DOI: 10.1016/j.aap.2007.06.006

23. Kim J., Ulfarsson G.F., Shankar V.N., Mannering F.L. (2010). A note on modeling pedestrian-injury severity in motor-vehicle crashes with the mixed logit model. Accid Anal Prev., 42(6):1751-8, DOI: 10.1016/j. aap.2010.04.016

24. Huang H., Abdel-Aty M.A., Darwich A.L. (2010). County-Level Crash Risk Analysis in Florida: Bayesian Spatial Modeling. Transp Res Rec., 2148(1):2737, DOI: 10.3141/2148-04

25. Abdel-Aty M.A. (2003). Analysis of driver injury severity levels at multiple locations using ordered probit models. J Safety Res., 34, DOI: 10.1016/j. jsr.2003.05.009

26. Quddus; M.A, Wang C., Ison S.G. (2010). Road Traffic Congestion and Crash Severity: Econometric Analysis Using Ordered Response Models. J Transp Eng.,136(5), DOI: https://doi.org/10.1061/(ASCE) TE.1943-5436.0000044

27. Aziz H.M.A., Ukkusuri S.V., Hasan S. (2013). Exploring the determinants of pedestrian-vehicle crash severity in New York City. Accid Anal Prev.,50:1298309, DOI: 10.1016/j.aap.2012.09.034

28. Greene, W. H. (2012). Econometric Analysis (Seventh ed.). Boston: Pearson Education. pp. 803-806. ISBN 978-0-273-75356-8.

29. Wang C., Quddus M.A., Ison S.G. (2013).The effect of traffic and road characteristics on road safety: A review and future research direction. Saf Sci., 57:264-75, DOI: 10.1016/j.ssci.2013.02.012.
30. Rankavat S., Tiwari G. (2016). Pedestrians risk perception of traffic crash and built environment features - Delhi, India. Saf Sci.,1-7, https://doi.org/10.1016/j. ssci.2016.03.009

31. Chen S., Saeed T.U., Alinizzi M, Lavrenz S., Labi S. (2019). Safety sensitivity to roadway characteristics: A comparison across highway classes. Accid Anal Prev;123:39-50. https://doi.org/10.1016/j. aap.2018.10.020

32. Fotios S. (2019). Road lighting and the detection of slip hazards when walking. Light Res Technol., 51(2):324-5, DOI: 10.1177/1477153519837893.

33. Siregar M.L., Alawiyah T., Tjahjono T.. Remedial safety treatment of accident-prone locations. Int J Technol. 2015;6(4). DOI: 10.14716/ijtech.v6i4.1097

34. Lee C., Abdel-Aty M. (2005). Comprehensive analysis of vehicle-pedestrian crashes at intersections in Florida. Accid Anal Prev., 37(4):775-86, DOI: 10.1016/j.aap.2005.03.019.

35. Borowsky A., Oron-Gilad T, Meir A., Parmet Y. (2012). Drivers' perception of vulnerable road users: A hazard perception approach. Accid Anal Prev., 44(1):160-6, DOI: 10.1016/j.aap.2010.11.029 .

36. Gitelman V., Doveh E., Carmel R., Pesahov F. (2014). The Relationship Between Road Accidents and Infrastructure Characteristics of Low-Volume Roads in Israel. In: Proceedings of Second International Conference on Traffic and Transport Engineering (ICTTE). Belgrade: Transportation Research Board, p. 350-8.

37. Vorko-Jovic A., Kern J., Biloglav Z. (2006). Risk factors in urban road traffic accidents. J Safety Res., 37, DOI: 10.1016/j.jsr.2005.08.009.

38. Demetriades D., Murray J., Martin M., Velmahos G., Salim A. Alo K., et al. (2004). Pedestrians injured by automobiles relationship of age to injury type and severity. J Trauma, 199:382-7, DOI: 10.1016/j.jamcollsurg.2004.03.027.

39. Kröyer H.R.G. (2015). Is 30 km/h a 'safe' speed? Injury severity of pedestrians struck by a vehicle and the relation to travel speed and age. IATSS Res., 39(1):42-50, DOI: 10.1016/j.iatssr.2014.08.001 .

Paper submitted: 11.06.2019.

Paper accepted: 14.09.2019.

This is an open access article distributed under the CC $B Y-N C-N D 4.0$ terms and conditions. 